REVISTA X, Curitiba, volume 13, n.1, p.9-34, 2018.

Dossiê Especial: Português como Língua Adicional em contextos de minorias:

(co)construindo sentidos a partir das margens

BIZON \& DINIZ (Orgs.)

\title{
A APRENDIZAGEM DE PORTUGUÊS POR IMIGRANTES DESLOCADOS FORÇADOS NO BRASIL: UMA OBRIGAÇÃ̃O?
}

\section{Learning Portuguese as a Welcoming Language for Forced Displaced Immigrants in Brazil: an obligation?}

RESUMO: Este trabalho busca discutir o ensino-aprendizagem da especialidade de Português como Língua de Acolhimento (PLAc) para imigrantes deslocados forçados no Brasil, com vistas a questionar o caráter de necessidade obrigatória com o qual sua aprendizagem é geralmente associada. Para alcançar tais objetivos, realizaremos uma análise de cunho qualitativo e interpretativista do discurso de profissionais da área professores e coordenadores de diferentes cursos de PLAc no país -, bem como de alguns imigrantes, no que diz respeito às motivações para se aprender a língua majoritária do Brasil. $\mathrm{O}$ artigo está organizado da seguinte maneira: primeiramente, faremos uma breve exposição do cenário da imigração de deslocados forçados, evidenciando a relevância do tema. Em segundo lugar, apresentaremos alguns conceitos pertinentes que respaldam teoricamente as discussões realizadas. Em terceiro lugar, analisaremos o discurso dos participantes da pesquisa, visando discutir como a aprendizagem do PLAc é entendida como uma necessidade obrigatória, e como esse discurso pode oprimir sujeitos deslocados forçados, reforçando sua situação de vulnerabilidade. Finalizaremos nosso texto discorrendo sobre como certas perspectivas de trabalho com o PLAc, indo de encontro à primeira perspectiva, podem colaborar para processos de territorialização não-precária (BIZON, 2013) desses imigrantes.

PALAVRAS-CHAVE: Português como Língua de Acolhimento; Imigrantes Deslocados Forçados; (Re)territorialização; Educação de Grupos Minoritarizados; Vulnerabilidade.

ABSTRACT: The present study seeks to discuss the teaching and learning process of Portuguese as a Welcoming Language for forced displaced immigrants in Brazil (hereinafter referred to as $P W L g$ - or PLAc, in Portuguese), aiming to question the character of obligatory need with which its learning is generally associated to. To achieve such objectives, we will carry out a qualitative and interpretative analysis of the discourse of professionals from the area - teachers and coordinators of different PWLg

\footnotetext{
${ }^{1}$ Este artigo retoma e aprofunda discussões já empreendidas em nossa pesquisa de mestrado (LOPEZ, 2016).

2 Doutoranda no Programa de Pós-graduação em Estudos Linguísticos da UFMG. Atualmente é professora voluntária na Universidade Federal de São João del-Rei (UFSJ) e colaboradora da Universidade da Geórgia (UGA). Email: lopez.anap@gmail.com
} 
REVISTA X, Curitiba, volume 13 , n.1, p.9-34, 2018.

Dossiê Especial: Português como Língua Adicional em contextos de minorias:

(co)construindo sentidos a partir das margens

BIZON \& DINIZ (Orgs.)

courses in the country - as well as some immigrants, regarding the motivations for learning the Brazilian majority language. The paper is, therefore organized as follows: first, we will give a brief exposition of the immigration scenario of forced displaced people, highlighting the relevance of the theme. Second, we will present some relevant concepts that theoretically support such our discussions. Third, we will analyze the participants' discourse, aiming to discuss how the learning of PWLg is understood as an obligatory need, intending to discuss how this discourse may oppress forced displaced immigrants, reinforcing their vulnerability status. We will finish our text by discussing how certain perspectives for PWLg, opposed to the first perspective, can collaborate for non-precarious territorializations processes (BIZON, 2013) of immigrants.

KEY-WORDS: Portuguese as Welcoming Language; Forced Displaced Immigrants; (Re)territorialization; Education for Minoritized Groups; Vulnerability.

\section{INTRODUÇÃO E FORMULAÇÃO DO PROBLEMA}

No ano de 2017, a humanidade atingiu um novo recorde ${ }^{3}$ no complexo panorama das migrações internacionais consideradas como de crise (CLOCHARD, 2007) ${ }^{4}$ : segundo dados do Alto Comissariado das Nações Unidas para Refugiados (ACNUR), 68,5 milhões de pessoas, dentre as quais 52\% com idade inferior a 18 anos, deslocaramse forçadamente em razão de "perseguição, conflito, violência ou violação dos Direitos Humanos" (UNHCR, 2018). Atualmente, o Brasil abriga 8.863 refugiados de 79 nacionalidades diferentes ${ }^{5}$, originários principalmente da Síria, Angola, Colômbia e República Democrática do Congo, de acordo com dados do relatório do Comitê Nacional para os Refugiados - CONARE (CONARE, 2016). Esse número seria ainda maior se considerássemos os imigrantes originários de outros processos de migração forçada não contemplados, na legislação brasileira vigente, pela categoria de refugiado:

\footnotetext{
3 Desde o período posterior à Segunda Guerra Mundial, quando o ACNUR iniciou suas estatísticas (ACNUR, 2017).

${ }^{4}$ Para Clochard (2007), as migrações de crise são aquelas em que as pessoas se deslocam forçadamente, motivadas por crises humanitárias ou por confrontos políticos, ideológicos e militares. Muitas vezes, nos países de destino - principalmente, nos do "Norte" -, tais migrantes são vítimas de discriminação, sendo considerados indesejáveis e tidos ou tratados como ilegais.

${ }^{5}$ Embora não haja um comunicado oficial do CONARE, informações veiculadas na mídia sugerem que o número de refugiados reconhecidos no país seja maior, tendo em vista as solicitações aprovadas no ano de 2017, quando 40,1\% das 1.179 solicitações de refúgio foram aprovadas, segundo dados obtidos pelo G1 por meio da Lei de Acesso à Informação. Dentre as nacionalidades dos solicitantes aprovados, encontram-se sírios (230 pessoas), congoleses (108), palestinos (26), egípcios (16) e paquistaneses (13). Disponível em: <https://g1.globo.com/mundo/noticia/brasil-aprovou-40-das-solicitacoes-de-refugioanalisadas-em-2017.ghtml>. Acesso em: 29 jan. 2018.
} 
REVISTA X, Curitiba, volume 13 , n.1, p.9-34, 2018.

Dossiê Especial: Português como Língua Adicional em contextos de minorias:

(co)construindo sentidos a partir das margens

BIZON \& DINIZ (Orgs.)

é o caso dos haitianos e venezuelanos, por exemplo, que somam cerca de 85 mil (MJC, 2016) e entre 40 e 60 mil habitantes (CHARLEAUX, 2018), respectivamente, no país ${ }^{6}$. Aos nacionais do Haiti, têm sido fornecidos vistos de caráter humanitário, enquanto venezuelanos podem solicitar residência por serem originários de país fronteiriço, apesar de muitos imigrantes dos dois países ingressarem no Brasil como solicitantes de refúgio ${ }^{7}$.

Além de impactar a dinâmica populacional do país (OLIVEIRA, 2015), esses novos movimentos de imigração para o Brasil têm sido foco de interesse na agenda de diferentes agentes governamentais e não governamentais. Isso pode ser comprovado por meio de avanços tais como aqueles alcançados pela legislação, em âmbito nacional, com a aprovação - ainda que com vetos ${ }^{8}$ - da nova Lei de Migração n. ${ }^{\circ}$ 13.445/17 (BRASIL, 2017a), ou em âmbito municipal, com a ação pioneira da cidade de São Paulo ao aprovar sua Política Municipal para a População Imigrante ${ }^{9}$. Além disso, testemunhamos um crescente número de universidades brasileiras que têm estreitado relações com o ACNUR - por meio da Cátedra Sérgio Vieira de Mello - e têm se dedicado a ações de pesquisa, ensino, extensão, entre outras, para deslocados forçados (ACNUR, 2017; BAZZO; FAJARDO, 2017; LOPEZ; DINIZ, no prelo).

É preciso ressaltar, entretanto, que, apesar de certa preocupação, por parte do governo, com a regulamentação jurídica dos deslocados forçados, o Estado brasileiro tem feito pouco para efetivamente recepcionar essas pessoas no país, comparativamente com outros países cujos governos possuem políticas de acolhimento mais estruturadas, como é o caso de Portugal, França e Alemanha (AMADO, 2013; LOPEZ, 2016; OLIVEIRA; SILVA, 2017; SÃO BERNARDO, 2016), ainda que tais políticas sejam,

\footnotetext{
6 Dessa forma, por seus processos de migração não serem considerados, necessariamente, como motivados devido à perseguição ou violação de direitos humanos, os imigrantes haitianos (assim como senegaleses e bengalis, dentre outros) não recebem o status de refugiado, mas permanecem no país por meio de vistos de caráter especial. Para uma discussão mais abrangente sobre o tema, cf. LOPEZ (2016).

${ }^{7}$ Até março de 2016, um total de 48.371 solicitações de refúgio haviam sido registradas por parte de haitianos, segundo dados do Departamento de Polícia Federal apresentados pelo CONARE (2016). Segundo reportagem de Charleaux (2018), cerca de 22 mil venezuelanos solicitaram refúgio no Brasil.

${ }^{8}$ Cf. Delfim (2017), disponível em: <http://migramundo.com/nova-lei-de-migracao-e-sancionada-masvetos-derrubam-anistia-e-mais-19-pontos/>. Acesso em: 25 set. 2017.

9 Disponível em: <http://www.acnur.org/portugues/noticias/noticia/sao-paulo-aprova-sua-propria-leipara-refugiados-e-imigrantes/>. Acesso em: 25 set. 2017.
} 
REVISTA X, Curitiba, volume 13 , n.1, p.9-34, 2018.

\section{Dossiê Especial: Português como Língua Adicional em contextos de minorias:}

(co)construindo sentidos a partir das margens

BIZON \& DINIZ (Orgs.)

com frequência, marcadas por motivações assimilacionistas ${ }^{10}$ e certos equívocos (ANUNCIAÇÃO, 2017; 2018). Diante disso, é importante reiterar que a orientação e socialização inicial desses imigrantes no Brasil tem sido mérito da sociedade civil, que atua por meio de organizações não-governamentais (ONGs), grupos religiosos e associações (BIZON; CAMARGO, 2018). Tais instituições, além de oferecerem moradia inicial, alimentação, instrução jurídica, assistência médica e laboral aos imigrantes (AMADO, 2013), também são responsáveis, na maioria das vezes, pelo ensino da língua portuguesa para o público formado por deslocados forçados especialidade que tem sido designada como Português como Língua de Acolhimento (PLAc), foco de interesse do presente trabalho. Nos últimos anos, têm sido dados os primeiros passos para a consolidação dessa área de pesquisa e ensino, com cada vez mais investigações sendo conduzidas, nos âmbitos da graduação e pós-graduação, e cursos de língua voltados a esse público sendo oferecidos por Instituições de Ensino Superior (IES) brasileiras (LOPEZ; DINIZ, no prelo).

Destarte, considerando, em particular, a crescente atenção do governo e das IES para a questão dos deslocados forçados - ainda que de forma especial para os refugiados, cuja condição, por diversos motivos, provoca certa comoção social ${ }^{11}$-, acreditamos ser essencial o debate que propomos neste trabalho: questionar a maneira como o ensino de PLAc tem sido percebido e caracterizado no país. A nosso ver, o ensino de PLAc tem sido, frequentemente, significado por um viés de obrigatoriedade que, perigosamente, se esconde por trás de um discurso que, aparentemente, apenas sugere a necessidade de tal aprendizado. Por esse motivo, buscaremos discutir esse caráter de necessidade obrigatória no contexto de ensino de PLAc, por meio da análise de parte dos registros gerados por uma pesquisa de mestrado conduzida por nós anteriormente em Lopez (2016). Visaremos, ainda, discutir o conceito de vulnerabilidade - comumente colocado como uma característica dos imigrantes

\footnotetext{
${ }^{10}$ Por exemplo, foi alvo de críticas a proposta de lei anunciada pela Alemanha - cujo esboço foi aprovado em maio de 2016 - que estabelece a exigência de que imigrantes aprendam o alemão e se submetam a testes de proficiência, sob ameaça de perda de direitos de residência no país. Mais informações disponíveis em:< https://goo.gl/TX5oVR e https://goo.gl/0P9jY1 2 . Acesso em: 26 set. 2017.

${ }^{11}$ Cf. Baeninger (2017).
} 
REVISTA X, Curitiba, volume 13 , n.1, p. 9-34, 2018.

Dossiê Especial: Português como Língua Adicional em contextos de minorias:

(co)construindo sentidos a partir das margens

BIZON \& DINIZ (Orgs.)

deslocados forçados ${ }^{12}$ - e tentar esboçar uma possível relação desse fenômeno com o PLAc. Nosso objetivo principal é ressaltar como esse discurso pode funcionar de forma perversa e, no limite, servir para reforçar a situação de vulnerabilidade dos imigrantes deslocados forçados.

\section{PORTUGUÊS COMO LÍNGUA DE ACOLHIMENTO: ALGUMAS PONDERAÇÕES}

Embora trate do contexto de Portugal, acreditamos que o entendimento de Grosso (2010) sobre o PLAc também seja pertinente para a realidade brasileira embora algumas precauções para tal transposição sejam tomadas, como argumenta Anunciação (2017), sobre o que comentaremos mais adiante nesta seção. Apesar de reconhecer a heterogeneidade do público para o qual são direcionadas as ações em PLAc, Grosso (idem) acredita na existência de alguns pontos característicos desse grupo, que devem ser considerados no contexto de ensino de PLAc. São eles: a) variação do nível de proficiência em língua portuguesa, relacionada diretamente a um maior ou menor tempo de imersão linguística desde a chegada do imigrante do país (na sua realidade, a Portugal); b) variação de conhecimento de sua língua materna e da sua própria cultura, que, tem um impacto na aprendizagem da língua-cultura portuguesa; c) variação, dentre esses imigrantes, de conhecimento e de uso de outras línguas, o que, na visão da autora, impacta a aprendizagem do português, já que aqueles que detêm desse conhecimento teriam uma certa facilidade no aprendizado da língua portuguesa pela transferência de estratégias de comunicação e de aprendizagem; e, finalmente, d) variação socioeconômica, dado que os imigrantes apresentam diferenças de subvariação profissional, ou seja, na profissão em que atuavam antes de chegarem ao país de destino e naquelas que exerciam no contexto de origem.

\footnotetext{
12 Sendo "vulnerável", inclusive, o termo atribuído, pela legislação vigente, àqueles imigrantes que recebem isenção nas taxas para aquisição de documentos de regularização migratória, segundo o Decreto № 9.199 de 20 de novembro de 2017 (BRASIL, 2017b) que regulamenta a Lei no 13.445 , de 24 de maio de 2017, a qual institui a Lei de Migração (BRASIL, 2017a).
} 
REVISTA X, Curitiba, volume 13 , n.1, p.9-34, 2018.

\section{Dossiê Especial: Português como Língua Adicional em contextos de minorias:}

(co)construindo sentidos a partir das margens

BIZON \& DINIZ (Orgs.)

$\mathrm{Na}$ concepção dessa autora, esses pontos devem ser considerados pelo ensino de PLAc na medida em que podem determinar "a atitude em relação à cultura, ao país, à língua-alvo e aos seus falantes" (GROSSO, 2010, p. 68). Apesar de não ser o foco do presente trabalho, a nosso ver, acreditamos que seja necessária uma ponderação acerca do quesito "variação de conhecimento de sua língua materna e da sua própria cultura" proposto por Grosso (idem). É preciso problematizar que conceitos de "língua" e "cultura" estão em jogo quando se trata de determinar que um imigrante tem um maior ou menor grau de conhecimento sobre tais quesitos em comparação com um outro. Se consideramos a possibilidade de mensurar o conhecimento de alguém sobre determinada língua ou cultura, estamos considerando que ambos os conceitos sejam coisas pré-determinadas que seriam partilhadas pelos membros de uma mesma comunidade. Outrossim, na tentativa de determinar quantitativamente o conhecimento de alguém sobre suas própria língua e/ou cultura, é preciso estar atento para não reforçar a ideia equivocada de que existam representantes "autênticos" (MAHER, 2007) - os "modelos" para a avaliação - dessa língua e dessa cultura; dessa forma, essencializando-as. Nesse sentido, questionamos, ainda, como seria feita essa determinação e quem seria responsável por realizar tal julgamento.

Além disso, acreditamos que caberia acrescentar às características próprias desse grupo, propostas por Grosso (2010), outra particularidade que pode ter um impacto na maneira com a qual/pela qual os imigrantes aprendem (ou não) a língua portuguesa, que seria: e) variação dos percursos migratórios. Embora todos os imigrantes sob o escopo da terminologia "deslocado forçado" advenham de processos de migração forçada ou de crise, isso não significa que seus percursos migratórios sejam idênticos (motivações, migrações anteriores, redes de acolhida, etc.), pois se trata de um grupo heterogêneo (GROSSO, 2010). Assim, entendemos que tais percursos podem influenciar, sobremaneira, no aprendizado da língua majoritária do país de destino. Endossamos a opinião de Amado (2013), para quem os fatores extralinguísticos decorrentes do processo de refúgio - ou de deslocamento forçado -

podem gerar barreiras para o aprendiz da língua do país de acolhida. As perspectivas individuais sobre a língua-alvo, a sua autoimagem, os planos para o futuro, como a necessidade urgente de aprendizagem para inserção no 
REVISTA X, Curitiba, volume 13 , n.1, p.9-34, 2018.

Dossiê Especial: Português como Língua Adicional em contextos de minorias:

(co)construindo sentidos a partir das margens

BIZON \& DINIZ (Orgs.)

mercado de trabalho e integração na sociedade, podem criar dificuldades no processo de aprendizagem. A própria tensão do movimento migratório de fuga, somada, muitas vezes, ao afastamento dos laços familiares e linguístico-culturais, também pode contribuir para essa situação (AMADO, 2013, s/p).

Destacamos que, embora seja interessante pensar nas variações de que trata Grosso (ibidem), elas não são exclusivas do PLAc e, como tais, também podem ser observadas em outros contextos de ensino de Português como Língua Estrangeira/Adicional (PLE/PLA) - inclusive para outros grupos de imigrantes que, possivelmente, estejam em situação de vulnerabilidade mesmo não fazendo parte do grupo de refugiados ou portadores de visto humanitário, como é, frequentemente, o caso de imigrantes candidatos ao Programa Estudantes-Convênio de Graduação (PEC-G) ${ }^{13}$, por exemplo. Isso aponta para a dificuldade que observamos em conceitualizar e delimitar o que seria, especificamente, o PLAc.

Entendemos que o termo língua de acolhimento tem sido utilizado para se referir a contextos de ensino-aprendizagem que contam com alunos deslocados forçados, na atual conjuntura das migrações transnacionais do séc. XXI (BAENINGER; PERES, 2017). Ainda que a prática em PLAc possa ser, em certos contextos, realizada de forma semelhante a outras de PLE/PLA de maneira geral, acreditamos na necessidade de utilizarmos uma designação diferente pelo ato político que isso representa. Dessa forma, embora seja um termo sloganizado ${ }^{14}$ (ANUNCIAÇÃO, 2017; 2018), confiamos sempre atentos à necessidade de problematização ao se transplantar o termo do contexto europeu para o brasileiro (ibidem) - na indispensabilidade de marcar esse cenário de ensino-aprendizagem, pesquisa e extensão para imigrantes deslocados forçados - ou outros imigrantes que, ocasionalmente, se encontrem em situação de minoritaridade ${ }^{15}{ }_{-}$

\footnotetext{
${ }^{13}$ A esse respeito, cf. Bizon (2013) e Miranda (2016).

14 Anunciação (2017), retomando os estudos de Viebrock (2014), define sloganização como "um resultado da simplificação, isto é - deliberadamente ou não -, apropriar-se de conceitos ou de partes de textos fora de seu contexto textual ou histórico, trabalhando, consequentemente, com uma versão reduzida [deles]" (ANUNCIAÇÃO, 2017, p. 33, tradução da autora).

${ }^{15}$ Conforme utilizamos em trabalhos anteriores, optamos por utilizar a noção de "minoritarizado no lugar de minoritário, com vistas enfatizar a condição de 'minoritário' como consequência de um processo sóciohistórico e político de opressão, de destituição de direitos e/ou acessos, transpassado por relações de poder" (LOPEZ, 2016, p. 43).
} 
REVISTA X, Curitiba, volume 13 , n.1, p. 9-34, 2018.

Dossiê Especial: Português como Língua Adicional em contextos de minorias:

(co)construindo sentidos a partir das margens

BIZON \& DINIZ (Orgs.)

como uma especialidade na esfera do PLA e que, como tal, requer uma designação própria. Sendo assim, reiteramos, a seguir, nossa definição dessa especialidade:

Entendemos PLAc como a ramificação da subárea de Português como Língua Adicional (PLA) - integrante, portanto, da área de Linguística Aplicada que se dedica à pesquisa e ao ensino de português para imigrantes, com destaque para deslocados forçados, que estejam em situação de vulnerabilidade e que não tenham o português como língua materna. Seu objetivo é a produção e circulação de saberes linguístico-discursivos que, em última instância, contribuam para "produzir e democratizar mobilidades e multiterritorialidades", fazendo face a processos de "reterritorialização precária" (BIZON, 2013, p. 123). Daí a necessidade imperativa de um olhar sempre problematizador, que lance dúvidas sobre certezas que facilmente podem ir se construindo na especialidade em questão. / O PLAc não pode ser visto como uma mera "adaptação" de saberes já produzidos para um novo contexto de ensino-aprendizagem. Ao contrário, professores e pesquisadores necessitam se interrogar, a todo momento, quem são esses sujeitos migrantes, quais são as relações que estabelecem com os diferentes territórios e línguas que (os) constituem e como se pode dar o ensino de português para esse público. Interrogações que, junto a outras, se alimentam de - ao mesmo tempo em que podem fomentar - discussões na LA de maneira mais geral, e no PLA de maneira particular. Nesse sentido, o PLAc é uma especialidade transdisciplinar, que demanda um contínuo diálogo com diferentes campos a exemplo da Antropologia, da Ciência Política, das Ciências Sociais, do Direito, da Geografia, da História, da Linguística, da Psicologia, da Psicanálise e das Relações Internacionais -, bem como com distintas entidades da sociedade civil [...]. (LOPEZ; DINIZ, no prelo, s/p).

Por acreditarmos na necessidade de esclarecimento sobre o conceito de vulnerabilidade, que não raramente aparece na literatura sobre migração forçada e, atualmente, na literatura em PLAc, gostaríamos de dedicar a próxima seção à discussão do tema. 
REVISTA X, Curitiba, volume 13 , n.1, p.9-34, 2018.

Dossiê Especial: Português como Língua Adicional em contextos de minorias:

(co)construindo sentidos a partir das margens

BIZON \& DINIZ (Orgs.)

\section{OS IMIGRANTES DESLOCADOS FORÇADOS COMO GRUPO MINORITARIZADO E O CONCEITO DE VULNERABILIDADE}

Carmo $(2016)^{16}$ faz uma discussão sobre o conceito de minoria e suas intersecções com o de grupos vulneráveis que nos interessa aqui. Podemos considerar, grosso modo, ambos os termos como categorias sociais de identificação de conjuntos de pessoas que lidam com a opressão e a violência advindas de processos sociais desiguais, consequentes de relações de poder (CARMO, 2016). Concentrando-nos apenas na aproximação que o autor faz entre os dois conceitos - minoria e vulnerabilidade -, podemos entender um grupo minoritário (ou minoria) como a "particularização de um grupo" que faz face a uma maioria - não necessariamente demográfica - que, por sua vez, "se define por um agrupamento generalizado, ou seja, por um processo de generalização baseado na indeterminação de traços, os quais indicam um padrão de suposta normalidade, considerada majoritária em relação ao outro que destoar dele" (CARMO, 2016, p. 205). Para o autor, a situação de vulnerabilidade experienciada por esse grupo minoritário seria decorrente de "pressões desse suposto padrão de normalidade [de um grupo majoritário, ou seja, politicamente mais forte] que pressiona tudo e todos que possam ser considerados diferentes" (idem).

Ainda segundo Carmo (2016) - e esse é um ponto de grande valia para o nosso trabalho -, tais grupos sofrem processos de violência que podem se manifestar em sua forma física e, também, simbólica; esta última “originária dessa pressão, que, muitas vezes, na forma de preconceito e rejeição, marginaliza e discrimina o diferente" (ibidem, p. 206). É preciso estar atento, no entanto, para o fato de que minorias e populações vulneráveis possuem características comuns, mas não são equivalentes e, portanto, nem sempre mantêm relação conceitual. Concordamos com Carmo (idem, p. 203), para quem “o que parece comum [entre os dois grupos] está na estreita relação de afetamento no que tange

\footnotetext{
${ }^{16}$ A partir de uma perspectiva conceitual, o objetivo desse autor é discutir a problemática do uso do termo "tolerância" e sua relação com o discurso de ódio relacionados a grupos minoritários e vulneráveis no Brasil.
} 
REVISTA X, Curitiba, volume 13 , n.1, p.9-34, 2018.

Dossiê Especial: Português como Língua Adicional em contextos de minorias:

(co)construindo sentidos a partir das margens

BIZON \& DINIZ (Orgs.)

ao poder que lhes é tirado, ao processo de dominação, à violência sofrida, à marginalização social e a uma necessidade premente de tolerância ${ }^{17}[\ldots]$ ”.

Com base nessa discussão, preferimos adotar o termo grupo minoritarizado no lugar de "minoritário" ou "minoria" para sinalizar o afastamento do sentido demográfico que tais palavras eventualmente podem criar e, principalmente, para enfatizar que minoritarizado é uma condição - e não algo inerente - de um grupo, decorrente de diferentes processos sociais, históricos e políticos, tais como os mencionados por Carmo (op. cit.), não isentos de relações de poder (CAVALCANTI, 2009 apud SEMECHECHEM, 2010). Diante disso, consideramos os deslocados forçados como grupos com potencial de minoritarização no Brasil ${ }^{18}$.

No que tange à questão de sua condição de vulnerabilidade - comumente associada a esse grupo, tanto na literatura sobre migrações internacionais, em geral, quanto naquela concernente ao ensino de PLA/PLE ou PLAc para esse público -, consideramos necessárias algumas ponderações sobre esse complexo conceito.

Para Sá e Fernandes (2016), fatores de vulnerabilidade, além de serem, muitas vezes, causa para migração, também se expressam no interior dos grupos de migrantes no país de destino, ainda que em maior ou menor grau. Segundo os autores, "desigualdade de gênero, preconceito étnico-racial, segregação residencial e baixos níveis de renda estão entre os principais fatores associados à vulnerabilidade de grupos migrantes" (ibidem, $\mathrm{s} / \mathrm{p}$ ). Assim, para que um imigrante seja capaz de lutar contra ou resistir a tais fatores de vulnerabilidade, é essencial que eles disponham de ativos. Nas palavras dos autores,

[o] conjunto de recursos materiais e imateriais dos quais indivíduos e lugares podem dispor são denominados ativos (KATZMAN, 2000, p. 294) e incluem capital físico, social e humano, que podem se manifestar através de direitos, vínculos sociais, habilidades e competências (idem, p. 295-296). Estes recursos permitem aos indivíduos e grupos acessar a estrutura de

17 Carmo (2016) acredita que a ideia de tolerância no tratamento das diferenças sociais não traz benefícios para as relações entre pessoas, senão malefícios, pois essa concepção funcionaria, paradoxalmente, para sustentar um discurso de ódio.

${ }^{18}$ É importante reiterar que adotamos uma concepção não-totalizadora (MAHER, 2007), reconhecendo a existência de diferenças intraculturais (idem); assim, acreditamos que indivíduos desse mesmo grupo possam ser minoritarizados e/ou vulneráveis de formas diferentes, pesando-se, por exemplo, relações que envolvam questões de nacionalidade, situação econômica, cor da pele e etnia, etc. 
REVISTA X, Curitiba, volume 13 , n.1, p.9-34, 2018.

\section{Dossiê Especial: Português como Língua Adicional em contextos de minorias:}

(co)construindo sentidos a partir das margens

BIZON \& DINIZ (Orgs.)

oportunidades oferecidas pelo Estado, pelo mercado e pela comunidade, a fim de melhorar o bem estar, evitar a deterioração das condições de vida ou diminuir a vulnerabilidade (SÁ \& FERNANDES, 2016, s/p).

Nesse sentido, Sá e Fernandes (2016), retomando os estudos de Katzman e Filgueira (1999), declaram que os recursos "se convertem em ativos à medida que as oportunidades oferecidas pelo mercado, pelo Estado e pela sociedade são aproveitadas" (idem, s/p). As oportunidades, por sua vez, "manifestam-se sob forma de estruturas, tais como 'empregos de boa qualidade', por meio das quais o acesso a certos serviços, bens ou atividades abre portas para outras oportunidades" (ibidem). Esses autores ressaltam, ainda em consonância com Katzman e Filgueira (1999), que as oportunidades variam no tempo e espaço, podendo, ou não, estarem disponíveis para o imigrante aproveitá-las.

Diante disso, percebe-se que a vulnerabilidade não é um fator interno, constituinte do sujeito ou lugar, apenas (MARANDOLA JR; HOGAN, 2006, p. 40). Mais do que isso, os riscos e perigos que ameaçam o indivíduo são fatores externos que esbarram na "preparação" do indivíduo para responder a tais ameaças. Para Caro (2003), a análise da vulnerabilidade social não pode considerar apenas os fatores de risco que ameaçam o indivíduo, mas deve envolver outras duas dimensões que, para nós, fazem parte do que chamamos de "preparação": a capacidade de resposta e as habilidades adaptativas do sujeito na situação de vulnerabilidade. Na visão dessa autora, a capacidade de resposta inclui possuir ativos e mecanismos de apoio externo (tanto governamentais, como políticas públicas favoráveis e programas do Estado, quanto não-governamentais, como a ajuda da sociedade civil ou ONGs), enquanto a adaptação seria algo, a nosso ver, de uma natureza subjetiva, como a aceitação das mudanças e/ou resiliência.

A vulnerabilidade advém, portanto, além dos fatores externos, dessa relação entre "preparo" e "defesa", ou seja, quanto mais capacidade de resposta um grupo ou indivíduo dispõe, menos vulnerável ele se torna. Sá e Fernandes (2016) citam que, na concepção da Comissão Econômica para a América Latina (CEPAL),

os grupos socialmente vulneráveis envolvem indivíduos que, por algum fator contextual, enfrentam circunstâncias adversas para inserção social e desenvolvimento pessoal, ou que apresentam algum atributo básico, tal como 
REVISTA X, Curitiba, volume 13 , n.1, p.9-34, 2018.

\section{Dossiê Especial: Português como Língua Adicional em contextos de minorias:}

(co)construindo sentidos a partir das margens

BIZON \& DINIZ (Orgs.)

a condição étnica, que os exponha a riscos ou problemas impeditivos da adoção de estratégias de desenvolvimento (CEPAL-ECLAC, 2002 apud SÁ \& FERNANDES, 2016, s/p).

Acreditamos ser esse o ponto em que a problemática da vulnerabilidade se encontra com a questão do PLAc. Diante do que foi exposto, para nós, na base da concepção de PLAc, o conhecimento da língua portuguesa deveria ser entendido como um ativo do qual o imigrante poderia se valer para aproveitar oportunidades e aumentar sua capacidade de resposta, consequentemente, servindo como ferramenta para diminuir sua vulnerabilidade. Se a língua portuguesa é importante para a inserção social dos imigrantes deslocados forçados no Brasil - conforme afirma Anunciação (2017), o (não) conhecimento da língua portuguesa "constitui-se em elemento-chave no processo de inserção social de migrantes e refugiados, o que tem implicações diretas sobre as possibilidades de exercício de agência" (idem, p. 95) -, logo, entendemos que o PLAc pode funcionar como um - apesar de não ser o único - recurso para superar, por meio de sua agentividade, situações de risco ou perigo, tornando os imigrantes, nesse sentido, menos vulneráveis.

Diante disso, acreditamos que PLAc deve ser uma prática de ensinoaprendizagem crítica, orientada para - mas não restrita a - deslocados forçados, extensiva para outros grupos de imigrantes em condição de minoritarizados ou de vulnerabilidade que desejem aprender a língua majoritária do Brasil, como mencionamos no nosso entendimento do termo supracitado. Em nossa perspectiva, o conhecimento do idioma é mais um ativo do qual o indivíduo pode lançar mão para melhorar sua condição de vida e/ou diminuir sua vulnerabilidade, pois aumenta sua capacidade de resposta. Assim, afastamo-nos de uma prática que, ainda que não intencionalmente, frequentemente se pauta pelo discurso da obrigatoriedade, ocultada pela "evidência" da necessidade que o imigrante deslocado forçado teria em aprender a língua portuguesa.

Tendo realizado tal reflexão sobre os conceitos de grupos minoritarizados e a questão da vulnerabilidade, passaremos, na próxima seção, às análises para melhor exemplificarmos o que afirmamos aqui: o ensino de PLAc pode ser, ao mesmo tempo, 
REVISTA X, Curitiba, volume 13 , n.1, p.9-34, 2018.

\section{Dossiê Especial: Português como Língua Adicional em contextos de minorias:}

(co)construindo sentidos a partir das margens

BIZON \& DINIZ (Orgs.)

encarado como um recurso, um ativo (SÁ; FERNANDES, 2016), que, consequentemente, abriria espaço para o exercício de (re)existência (ANUNCIAÇÃO, 2017; 2018), ou uma obrigação que pode acabar se tornando mais um lugar de opressão.

\section{O ENSINO DE PLAc NO BRASIL: UMA OBRIGAÇÃO?}

Conforme já mencionamos anteriormente, os registros utilizados neste trabalho foram retirados de nossa dissertação de mestrado (LOPEZ, 2016), em que realizamos uma pesquisa qualitativa de cunho etnográfico e interpretativista, gerando registros a partir da observação-participante no contexto de ensino-aprendizagem de PLAc e da aplicação de questionários semi-abertos (físicos e digitais) para dois grupos: o primeiro composto por coordenadores, professores e alunos de duas iniciativas de PLAc - uma oferecida por uma ONG e outra por um centro de extensão acadêmica - ambas localizadas em Belo Horizonte-MG; e o segundo grupo contando com a participação de coordenadores e professores de cursos de PLAc desenvolvidos em outras regiões do país. Para a condução das análises e discussões engendradas no presente trabalho, optamos por fazer um recorte dos registros gerados por meio dos referidos questionários físicos (no caso dos imigrantes) e digitais (no caso dos profissionais - professores e coordenadores) focando, especificamente, os discursos em que imigrantes e profissionais da área apresentaram certas imagens sobre qual seria o papel da língua portuguesa no processo de acolhimento dos deslocados forçados no Brasil. A escolha dos recortes foi orientada por sua relevância para a discussão que desenvolvemos aqui, cujo objetivo é questionar o viés de obrigatoriedade pelo qual a aprendizagem de PLAc tem sido encarada por alguns indivíduos que atuam no contexto pesquisado, neste caso, alunos, professores e coordenadores de PLAc.

Conforme buscaremos mostrar nas análises que apresentaremos a seguir, o ensino para imigrantes deslocados forçados no Brasil PLAc tem tomado alguns contornos que o posiciona ora como necessidade, ora como obrigação ou, na maioria das vezes, como uma combinação das duas coisas. Nesta parte do texto, objetivamos, sobretudo, problematizar o discurso essencialista e totalizador que envolve a própria conceitualização do que seja PLAc. 
REVISTA X, Curitiba, volume 13 , n.1, p.9-34, 2018.

Dossiê Especial: Português como Língua Adicional em contextos de minorias:

(co)construindo sentidos a partir das margens

BIZON \& DINIZ (Orgs.)

Em razão de ser a língua oficial ${ }^{19}$ do país, é inegável que o português assuma um papel importante no processo de territorialização (LOPEZ, 2016) dos deslocados forçados no Brasil. Assim, conhecer o idioma, para o deslocado forçado cuja permanência no Brasil se dá principalmente mediante procedimentos jurídicos e burocráticos ${ }^{20}$ que se realizam via língua portuguesa, pode significar estar um "passo à frente" e fazer parte de um grupo conhecedor da língua majoritária, o idioma de poder e de prestígio no país. De acordo com alguns participantes de nossa pesquisa (LOPEZ, 2016):

[...] quando uma pessoa chega em um país estrangeiro é muito importante que ela fale

a língua do país, então ir para a aula de português é a primeira coisa para um imigrante fazer (Imigrante 4 , grifos nossos).

[...] é muito importante porque ele [o curso de português] permite cada imigrante no Brasil realizar suas necessidades (Imigrante 7, grifos nossos).

[...] fazer curso de português é importante para todos os imigrantes no Brasil porque se precisasse alugar uma casa você não saberia como pedir essa casa. Depois, se estivesse na rua e você precisasse comprar [alguma coisa] você não saberia como perguntar por isso. Tudo isso é importante (Imigrante 8, grifos nossos).

[...] porque se uma pessoa não fala português e ela está vivendo no Brasil como ela vai fazer para viver bem [?] se ela tiver um problema como ela vai fazer para se defender. Na minha opinião, é um curso que é importante para todos os imigrantes que estão vivendo no Brasil, especialmente para mim (Imigrante 9, grifos nossos).

Os trechos destacados acima revelam que, para esses imigrantes, a falta do conhecimento da língua portuguesa implica a impossibilidade de realizar diversas atividades cotidianas. Há, na base dessa crença, o reforço do lugar de prestígio da língua portuguesa no Brasil, uma vez que, para os imigrantes 4 e 8 , principalmente, o

\footnotetext{
${ }^{19}$ Segundo Diniz (2012), retomando os estudos de Payer $(1999,2007)$, língua nacional é aquela que funciona como um dos instrumentos do Estado na execução do seu "ideal de unidade jurídica", sendo "uma dimensão da linguagem que não se confunde, empírica ou teoricamente, com a da língua materna" (p.14). Já a língua oficial, conforme Diniz (2008) com base em Guimarães (s/d), é aquela "obrigatória tanto na relação dos cidadãos com o Estado quanto na relação deste com aqueles". No caso do Brasil, as línguas nacional e oficial se sobrepõem, apesar de isso não acontecer em outros espaços, e de nem sempre ter sido assim na própria realidade brasileira, uma vez que "o português só se constitui como língua nacional do Brasil no fim do século XIX, embora já aparecesse, desde o início da colonização efetiva, como língua oficial" (ibidem, p. 49-50).

${ }^{20}$ Para conhecer alguns dos procedimentos do processo de solicitação e concessão de refúgio via elegibilidade, cf. Lima et al. (2017).
} 
REVISTA X, Curitiba, volume 13 , n.1, p.9-34, 2018.

Dossiê Especial: Português como Língua Adicional em contextos de minorias:

(co)construindo sentidos a partir das margens

BIZON \& DINIZ (Orgs.)

português seria a "língua do país" e o que leva os imigrantes 7 e 9 a acreditarem que sem essa língua o indivíduo ficaria quase impossibilitado de realizar suas atividades cotidianas. Conforme os recortes anteriores sugerem, as atividades cotidianas ou de sobrevivência desses imigrantes se dão em contextos em que o português é a língua exigida - a língua majoritária, de poder e de prestígio $^{21}$ - e, portanto, para realizá-las, eles precisam desse idioma. Além disso, em alguns discursos dos imigrantes, o português aparece como um ativo importante para a superação do downgrading ${ }^{22}$ do mercado de trabalho:

meu objetivo é conseguir falar, escrever e ler bem a língua [portuguesa] para que eu consiga um trabalho na minha profissão e depois consiga continuar meus estudos no Brasil (Imigrante 6, grifos nossos).

[...] de qualquer maneira o curso de português é importante para aprender porque se tiver um emprego que você gostaria de conseguir e por causa da língua que não sabe falar, você não vai conseguir esse emprego (Imigrante 8, grifos nossos).

Isso nos leva a concluir que, para essas pessoas, o conhecimento da língua portuguesa funciona, de alguma maneira e em alguns casos - e longe de ser o ideal ${ }^{23}$-, como um meio de subsistência, principalmente para imigrantes que enfrentam longos processos burocráticos para a regulamentação de sua situação jurídica. Verifica-se, ainda, que o conhecimento da língua portuguesa é associado à ideia de ascensão social que, na prática, pode não se sustentar. A nosso ver, essa concepção reforça a ideia de obrigatoriedade do seu aprendizado, conforme podemos observar no discurso da imigrante 8 , a seguir:

fazer curso de português é importante para todos os imigrantes no Brasil porque se precisasse alugar uma casa você não saberia como pedir essa casa. Depois, se estivesse na rua, você precisa comprar [alguma coisa]

\footnotetext{
${ }^{21}$ Entendemos, ancorados pela discussão engendrada por Cavalcanti (1999), que nem todas as variações da língua portuguesa são consideradas de poder ou prestígio. No entanto, falamos em "poder" e "prestígio" da língua portuguesa em vista de seu papel como majoritária no país e em comparação com outras línguas minoritarizadas que o imigrante eventualmente possua em seu repertório.

${ }^{22}$ Termo utilizado como referência "à ocupação laboral em funções inferiores ao nível de qualificação" (SÁ; FERNANDES, 2016, s/p).

${ }^{23}$ Para Oliveira e Silva (2017), a necessidade quase que imposta ao imigrante no Brasil de ter que aprender a língua portuguesa para se comunicar com as instâncias governamentais e ter acesso a serviços públicos básicos - já que não há uma política linguística oficial por parte do governo que faça com que determinados serviços sejam prestados em idiomas diferentes do português, com a ajuda de intérpretes, por exemplo - é uma forma de violação de direitos humanos.
} 
REVISTA X, Curitiba, volume 13 , n.1, p.9-34, 2018.

Dossiê Especial: Português como Língua Adicional em contextos de minorias:

(co)construindo sentidos a partir das margens

BIZON \& DINIZ (Orgs.)

você não saberia como perguntar isso. Tudo isso é importante. [...] de qualquer maneira o curso de português é importante para aprender porque se tiver um emprego que você gostaria de conseguir e por causa da língua que não sabe falar, você não vai conseguir esse emprego (Imigrante 8, grifos nossos).

No recorte do discurso da imigrante 8 , percebe-se que o conhecimento da língua portuguesa é colocado como um grande entrave para a entrada no mercado de trabalho. Esse tipo de discurso também se manifesta no discurso de profissionais que apresentaremos em seguida neste trabalho, posicionando a língua como um obstáculo para o acesso a determinados direitos, serviços, oportunidades de trabalho, entre outros, além de ser representado como um impedimento para a inserção social do imigrante.

Tal lógica nos parece sinalizar uma questão que, para nós, é fundamental quando tratamos do ensino de línguas adicionais - especialmente do PLAc que atua com grupos minoritarizados e/ou vulneráveis e que precisa ser melhor investigada e desenvolvida: relações de poder entre nacionalidades e línguas. Não nos parece correto afirmar que o principal entrave do indivíduo deslocado forçado à inserção social ou, principalmente, a oportunidades de trabalho adequadas seja o pouco conhecimento da língua portuguesa, já que imigrantes nativos de países/nacionalidades prestigiadas - e que falam línguas de prestígio (CAVALCANTI, 1999) - conseguem, muitas vezes, ocupar posições profissionais de notoriedade mesmo com baixa proficiência em português.

Tal caráter de obrigatoriedade subjacente à necessidade que os imigrantes sentem em aprender a língua também se manifesta no discurso e profissionais dessa especialidade - coordenadores e professores, no caso deste trabalho - quando se referem à importância da aprendizagem de PLAc (cf. LOPEZ, 2016). Coordenadores, professores e alunos dessa área, no entanto, expuseram outros aspectos para justificar a relevância do conhecimento de PLAc, como pode ser observado pelos excertos destacados abaixo. Primeiramente, analisemos o discurso dos profissionais quando caracterizam o público-alvo de PLAc:

[...] Para além das questões culturais de aproximação, os imigrantes estão em busca de direitos básicos, como trabalho e moradia, e principalmente, estão em busca da reconstrução de suas dignidades humanas (Professora 1, grifos nossos). 


\section{Dossiê Especial: Português como Língua Adicional em contextos de minorias: (co)construindo sentidos a partir das margens BIZON \& DINIZ (Orgs.)}

Os alunos de PLAc estão no Brasil por motivos muito diferentes de outros alunos de cursos de PLA. A grande maioria não veio para o Brasil porque quis, mas porque teve que vir - e isso faz com que a relação deles com o português seja diferente [...] [...] vejo que eles [os alunos de PLAc] têm uma grande NECESSIDADE de aprender o português. Afinal, eles não estão "brincando" de vir morar no Brasil; eles PRECISAM reconstruir a vida deles aqui, em um país em que se fala uma língua diferente da deles, sem ter um porto seguro para voltar, caso dê errado [...] (Professora 3, grifos nossos).

São alunos em situação de vulnerabilidade (alguns mais, outros menos), que não estão longe de seu país e seus familiares por opção, mas pela falta dela. Eles aprendem português por necessidade, para poder reconstruir sua vida em um país estranho com uma língua estranha (Professora 12, grifos nossos).

Esses alunos apresentam além das barreiras linguísticas, carências afetivas, econômicas e traumas psicológicos pertinentes para a sua imersão no país (Coordenadora 2, grifos nossos).

Conforme indicam as respostas das professoras e coordenadora anteriores, os alunos de PLAc podem ter demandas específicas porque são encarados como um público caracterizado, principalmente, por estarem em constante perda e/ou falta de algo (LOPEZ, 2016) - "perda de suas dignidades humanas", "falta de poder de escolha", "carências de diferentes naturezas". Como consequência desse discurso, a necessidade de uma inserção social, por meio da língua portuguesa, por parte desses imigrantes é considerada como algo imprescindível:

\footnotetext{
[...] visto esses alunos [os imigrantes deslocados forçados] chegarem ao Brasil com pouquíssimos recursos, em sua maioria. Mas, com o tempo, eles se tornam estrangeiros como tantos outros no Brasil e seus desejos por, por exemplo, continuarem seus estudos, abrirem negócios próprios e aperfeiçoarem sua proficiência na língua devem ser lembrados pelos professores e coordenadores dos cursos de PLAc (Coordenadora 1, grifos nossos).
}

O curso de PLAc recebe pessoas em situação de vulnerabilidade e, mais do que aprender a língua portuguesa, têm o desejo de serem integrados e fazer parte da sociedade brasileira. Portanto, o componente cultural, para além da gramática, é muito importante nesse sentido (Professora 9, grifos nossos).

Devido à ser voltado em grande parte para imigrantes e outras populações em situação de vulnerabilidade, que possam vir a sofrer preconceito ao tentarem se inserir na cultura e mercado de trabalho locais, a meu ver, o curso de acolhimento tem uma demanda maior pela inserção do aluno na cultura local, facilitando o processo de aculturação através de maior quantidade de conteúdo relacionado à linguagem não formal e manifestações culturais locais (Professora 13, grifos nossos).

O português é a língua do Brasil. A vida no Brasil é em português, das simples interações cotidianas ao contato com as instâncias superiores do Estado. Eles devem aprender o português se quiserem maiores chances que conquistar uma vida digna, que já é um desafio para grande parte da população nativa (Coordenador 5, grifos nossos). 
REVISTA X, Curitiba, volume 13 , n.1, p.9-34, 2018.

Dossiê Especial: Português como Língua Adicional em contextos de minorias:

(co)construindo sentidos a partir das margens

BIZON \& DINIZ (Orgs.)

Para a coordenadora 1, os deslocados forçados tornam-se, com o passar do tempo, "estrangeiros como tantos outros" o que implica que, a princípio, não são iguais. Para essa profissional, o ensino de PLAc deveria considerar os projetos de vida do imigrante - que podem não se diferir tanto daqueles de outros grupos de imigrantes ("estrangeiros como tantos outros") - e servir para colaborar com seu sucesso, com o que concordamos integralmente. $\mathrm{O}$ que problematizamos aqui é o fato de o conhecimento da língua ser afirmado quase como um requisito para que o deslocado forçado possa se inserir socialmente, realizar suas atividades e tocar sua vida.

Para a professora 9, o aprendizado da língua portuguesa é fundamental para "fazer parte da sociedade brasileira". Percebe-se, aqui, a língua como um forte fator para a integração social. Longe de negarmos a importância do idioma, problematizamos o discurso que, ao mesmo em que considera a aprendizagem do português como obrigatória pelo imigrante, não interroga a razão pela qual o Estado não cria meios de valorização e promoção das línguas dos imigrantes (OLIVEIRA; SILVA, 2017) ${ }^{24}$. Já para a professora 13, a assimilação seria positiva na medida em que preveniria que o deslocado forçado sofresse (ou continuasse sofrendo) preconceito, já que estaria apto a se "misturar", ou seja, na interpretação da professora, "aculturação" seria a adaptação à cultura local $^{25}$. O coordenador 5 reconhece a importância da língua portuguesa enquanto oficial (“a língua do Brasil”), mas afirma que os imigrantes devem aprender o português para serem capazes de concorrer com os brasileiros em busca da vida digna.

\footnotetext{
${ }^{24}$ Isso seria possível, já que alguns passos estão sendo tomados nesse sentido a exemplo da parceria entre a Secretaria Nacional de Justiça do Ministério da Justiça e a Universidade de Brasília para a utilização de intérpretes voluntários em entrevistas de solicitação de refúgio. Disponível em: $<$ http://www.brasil.gov.br/cidadania-e-justica/2017/ 12/entrevistas-de-solicitacao-de-refugio-vao-contarcom-interpretes-voluntarios >. Acesso em: 01 fev. 2018. Oliveira e Silva (2017) discorrem sobre a questão do voluntariado no panorama das políticas linguísticas para imigrantes no Brasil que, segundo os autores, está num patamar de quase inexistente.

${ }^{25}$ É preciso ponderar, ainda, que a assimilação - aqui usada como exemplo de uma "total" adaptação cultural - não é uma garantia real de bem-estar social. Segundo Arruda (2015, p 77), "mesmo sendo 'assimilado' esse processo não dá a eles [os imigrantes] uma posição de igualdade a nacionais naturais desse país. Esse tipo de processo pode estar associado à chamada 'assimilação segmentada', na qual grupos diversos passam por processos de inserção social diferenciados e acabam por ocupar postos e/ou status sociais específicos que podem levar à perpetuação de desigualdades sociais, não necessariamente 'consolidando' uma coesão social igualitária em um Estado-Nação" (ROGRÍGUEZ-GARCÍA, 2007, p. 23).
} 
REVISTA X, Curitiba, volume 13 , n.1, p.9-34, 2018.

\section{Dossiê Especial: Português como Língua Adicional em contextos de minorias:}

(co)construindo sentidos a partir das margens

BIZON \& DINIZ (Orgs.)

Entendemos que o coordenador esteja afirmando que o português é um recurso a mais para a conquista de condições de vida adequadas para a população migrante deslocada forçada, no entanto, preocupa-nos a noção de obrigatoriedade (expressa pelo uso da máxima "os imigrantes devem") subjacente a esse discurso ${ }^{26}$.

Observemos, adiante, o funcionamento da "necessidade compulsória" na fala dos imigrantes:

é como eu já falei, eu fiz ele [o curso de português] primeiro porque é um conhecimento a mais para mim, para que eu me defenda, para que eu decida sozinho uma coisa que eu quero ou não. Porque se eu sei falar a língua isso vai impedir as pessoas de falar qualquer coisa para mim, outras pessoas não vão poder me falar para fazer o trabalho que eu não deveria fazer/ que não é meu (Imigrante 2, grifos nossos).

[Decidi aprender o português] $1^{\circ}$ porque estou vivendo no país do Brasil $2^{\circ}$ para que eu possa me defender no país porque eu sou estrangeiro $3^{\circ}$ para que eu possa comunicar com todas as pessoas que querem comunicar comigo e para que eu possa trabalhar melhor (Imigrante 9, grifos nossos)

Para o imigrante 2, o português aparece como uma ferramenta potencializadora de autonomia (cf. "para que eu decida sozinho uma coisa que eu quero ou não") atrelada à um caráter de proteção (cf. "Porque se eu sei falar a língua isso vai impedir as pessoas de falar qualquer coisa para mim, outras pessoas não vão poder me falar para fazer o trabalho que eu não deveria fazer/ que não é meu"). Tal imagem do português como ferramenta de defesa pessoal está presente, também, quando o imigrante 9 fala sobre suas motivações para estudar o idioma: "para que eu possa me defender no país porque eu sou estrangeiro". Ou seja, o imigrante 9 se vê sob constante intimidação de que algo ruim possa lhe acontecer e, por isso, se sente na obrigação de estar preparado, por meio da língua portuguesa - a língua do seu potencial opressor - para ser capaz de se defender. Tal ameaça, nesta fala, especificamente, caracterizada pela figura desse "outro" - um alguém de quem é preciso estar preparado para se defender -, pode ser indício de um cerceamento de direitos.

Dessa forma, em situações como essa, as justificativas elencadas pelos imigrantes na busca de aprenderem português relacionam-se ao temor (à necessidade de defesa) ou, ainda, a uma obrigação imposta pela sociedade ao seu redor. Ou seja, ao

${ }^{26}$ Para uma discussão sobre a lógica da assimilação no discurso da inserção social, cf. Baeninger; Peres (2015). 
REVISTA X, Curitiba, volume 13 , n.1, p.9-34, 2018.

\section{Dossiê Especial: Português como Língua Adicional em contextos de minorias:}

(co)construindo sentidos a partir das margens

BIZON \& DINIZ (Orgs.)

invés de ser encarado como um ativo, ou seja, com um recurso a mais para superar situações de dificuldade, o conhecimento do idioma torna-se um palco para processos de violência simbólica que, no limite, podem agravar a situação de vulnerabilidade desse imigrante: se é senso comum que "todo indivíduo deslocado forçado deve saber português", logo, aqueles que não sabem/não têm interesse em aprender a língua poderão ser julgados e/ou pressionados por essa escolha, pois destoarão desse "suposto padrão" considerado a norma, aumentando, assim, sua vulnerabilidade.

Chegamos a essa conclusão com base em Carmo (2016), para quem, conforme mencionamos anteriormente, a situação de vulnerabilidade experienciada por um grupo minoritarizado é consequência de "pressões desse suposto padrão de normalidade que pressiona tudo e todos que possam ser considerados diferentes" (idem, p. 205). Logo, o discurso da obrigatoriedade da aprendizagem do português, muitas vezes ocultado por um discurso que apenas sugere a necessidade de tal aprendizagem, é, de certa forma, opressor.

Para justificar a conclusão de que a obrigatoriedade que opera por trás do discurso da necessidade é um tipo de violência que leva a uma vulnerabilidade, recorremos ao trabalho de Anunciação (2017). Segundo a autora, com base em Butler e Athanasiou (2013), o que está em jogo é uma autonomia heteronômica (condicionada) que se respalda nesse tipo de justificativa de que

\footnotetext{
para terem acesso à saúde, à educação e ao trabalho legalizado, recémchegados [populações migrantes e refugiadas] devem conhecer e praticar a cultura e a língua do país receptor, adequando seus comportamentos, corpos e linguagem, tornando-os apropriados (appropriate) para poderem ser reconhecidos como indivíduos que desfrutam de direitos e de recursos materiais e simbólicos (ANUNCIAÇÃO, 2017, p. 38).
}

Dessa forma, "paradoxalmente, ao invés de essas regras e normas do discurso neoliberal promoverem o acesso ao estado de bem-estar social e à inserção de migrantes e refugiados, elas reforçam violência simbólica contra grupos minoritarizados" (idem, p.38). Isto é, o aprendizado da língua, por esse viés, torna-se (mais) um mecanismo vinculado a processos de despossessão e não-reconhecimento violentos (idem). 
REVISTA X, Curitiba, volume 13 , n.1, p.9-34, 2018.

\section{Dossiê Especial: Português como Língua Adicional em contextos de minorias:}

(co)construindo sentidos a partir das margens

BIZON \& DINIZ (Orgs.)

Contudo, faz-se importante mencionar que o ensino de português, ao mesmo tempo em que pode funcionar como campo de opressão, pode também ser um espaço de (re)existência ${ }^{27}$ (ANUNCIAÇÃO, 2017) - neste último caso necessitando partir de uma perspectiva crítica e intercultural de ensino-aprendizagem de PLAc, como defendemos em Lopez (2016). Isso equivale a dizer que a língua portuguesa, enquanto língua nacional e majoritária no país (DINIZ, 2008) e mecanismo de reconhecimento do Estado (ANUNCIAÇÃO, 2017), pode ser uma barreira entre o imigrante e sua capacidade de resposta a situações de risco ou perigo ou, ainda, um dificultador da capacidade de aproveitamento das oportunidades (SÁ; FERNANDES, 2016) por parte dos deslocados forçados. Por outro lado, pode ser um território viabilizador de processos de territorialização não-precários (BIZON, 2016) e de práticas de (re)existência (ANUNCIAÇÃO, 2017; 2018), funcionando como um ativo a ser mobilizado para a diminuição de possíveis desvantagens sociais que o imigrante venha a enfrentar.

\section{CONSIDERAÇÕES FINAIS}

Embora não conte, ainda, com um ensino de PLAc institucionalizado (AMADO, 2013), o Brasil está dando seus primeiros passos para a mudança deste cenário (LOPEZ; DINIZ, no prelo). Devido à relevância do tema, a partir do momento em que o Brasil se torna rota de destino de fluxos migratórios transnacionais do séc. XXI, buscamos discutir, neste trabalho, como o ensino de português para esse público - PLAc assume, com frequência, um caráter de indispensabilidade implícita no discurso de imigrantes, professores e coordenadores de cursos para esse público. Analisamos, ainda, como esse funcionamento pode, de alguma maneira, contribuir para a situação de vulnerabilidade do imigrante, na medida em que se torna mais uma pressão propulsora de certa violência simbólica. Ao mesmo tempo, o ensino de PLAc pode contribuir para a emancipação desse migrante, sendo um lugar de realização de "práticas de

\footnotetext{
${ }^{27}(\mathrm{Re})$ negociação criativa e agentiva de sua(s) (nova(s)) identidade(s) (ANUNCIAÇÃO, 2017, p. 95).
} 
REVISTA X, Curitiba, volume 13 , n.1, p.9-34, 2018.

\section{Dossiê Especial: Português como Língua Adicional em contextos de minorias:}

(co)construindo sentidos a partir das margens

BIZON \& DINIZ (Orgs.)

(re)existência" (ANUNCIAÇÃO, 2017; 2018), ou seja, combatendo processos de territorialização precária (BIZON, 2013).

Evidentemente, para alcançar tais objetivos, o ensino de PLAc deve ser visto como uma prática fudamentao, principalmente, no fortalecimento político dos imigrantes e na educação do entorno, de modo a afastar-se de uma prática norteada por uma noção de obrigatoriedade (LOPEZ, 2016). É preciso considerar, ainda, que a língua pode não ser o único ativo que o imigrante em situação de vulnerabilidade precisa para superar tal circunstância, por isso há a necessidade de políticas públicas adequadas para a recepção e para o auxílio a esses indivíduos. A esse respeito, reiteramos as palavras de Oliveira e Silva (2017) para quem a problemática da questão "não está em querer que os imigrantes aprendam a língua oficial, pois, repetimos, essa é uma política indispensável e também um direito deles, mas em ver tal aprendizagem como a única política linguística possível" (idem, p. 148).

A nosso ver, os agentes responsáveis pelo ensino de PLAc no Brasil (ONGs, universidades, cursos livres ou instâncias governamentais) precisam estar cientes das consequências perversas desse tipo de discurso para não, involuntariamente, reforçá-lo. Ademais, é preciso reconhecer em que medida essa obrigatoriedade opera como violência simbólica para não acabar, paradoxalmente, causando ou reforçando a vulnerabilidade que busca superar.

Defendemos uma proposta de língua de acolhimento que mantenha um viés crítico, afastando-se de uma visão que posicione os seus aprendizes em um lugar prédeterminado de que precisam ser acolhidos - na perspectiva de "amparo" da palavra ou "integrados" - no sentido assimilacionista do termo. Destarte, acreditamos ser importante desnaturalizar os efeitos de evidência produzidos pelo discurso de necessidade imperativa discutido neste trabalho. Esperamos, dessa forma, contribuir para a consolidação do PLAc como uma especialidade crítica, plural, intercultural, translíngue e transdisciplinar que se afaste de noções / práticas assimilacionistas, contribuindo para a criação de uma política linguística com os mesmos pressupostos algo necessário, como apontado, de forma similar, por outros autores como Anunciação (2017), Oliveira e Silva (2017) e Sousa (2015). 
REVISTA X, Curitiba, volume 13 , n.1, p.9-34, 2018.

Dossiê Especial: Português como Língua Adicional em contextos de minorias:

(co)construindo sentidos a partir das margens

BIZON \& DINIZ (Orgs.)

\section{REFERÊNCIAS}

ACNUR. Cátedra Sérgio Vieira de Mello. 2017. Disponível em: <http://www.acnur.org/portugues/informacao-geral/catedra-sergio-vieira-de-mello/>. Acesso em: 02 out. 2017.

AMADO, R. S. O ensino de português como língua de acolhimento para refugiados. Revista da Sociedade Internacional Português Língua Estrangeir $a$. Edição 7, Ano 4, Número 2, 2013.

ANUNCIAÇÃO, R. F. M. A língua que acolhe pode silenciar? Reflexões sobre o conceito Português como Língua de Acolhimento. In: Revista X, Curitiba, v. 13, n.1, P. 35-56, 2018.

Somos mais que isso: práticas de (re)existência de migrantes e refugiados frente à despossessão e ao não reconhecimento. 2017. 127 f. Dissertação (Mestrado em Linguística Aplicada) - Instituto de Estudos da Linguagem, Universidade Estadual de Campinas, Campinas, 2017.

ARRUDA, A. M. O Estado como gestor dos fuxos migratórios: a inserção social do imigrante sob óticas tradicionais e novas tendências. Universitas Relações Internacionais, v. 13, n. 2, p. 67-81, Brasília de jul./dez. 2015.

BAENINGER, R. A. $7^{\circ}$ Diálogos no CEM: migração, refúgio e Direitos Humanos: travessias para uma vida digna? (mesa-redonda). Missão Paz: São Paulo, 2017. Disponível

em: <https://www.facebook.com/missaopazsaopaulo/videos/1404383829658518/>. Acesso em: 02 out. 2017.

BAENINGER, R.; PERES, R. Migração de crise: a migração haitiana para o Brasil. Revista Brasileira de Estudos de População. Belo Horizonte, v.34, n.1, pp.119-143, jan./abr. 2017.

SOS Português: imigração haitiana em São Paulo. GT 23 Migrações Internacionais: Legislações. Estados e Atores Sociais [anais eletrônicos]. Caxambu: $39^{\circ}$ Encontro anual da ANPOCS. 26 a 30 de outubro de 2015.

BAZZO, G.; FAJARDO, V. Universidades brasileiras matricularam cerca de 70 refugiados em menos de um ano, diz Acnur. G1 Educação. Disponível em: $<$ https://g1.globo.com/educacao/noticia/universidades-brasileiras-matricularam-cercade-70-refugiados-em-2016-diz-acnur.ghtml>. Acesso em: 28 set. 2017.

BIZON, A. C. C.; CAMARGO, H. R. E. Acolhimento e ensino de Língua Portuguesa à população oriunda de migração de crise no município de São Paulo: por uma política do atravessamento entre verticalidades e horizontalidades. In: BAENINGER, R.; BÓGUS, L. M.; MOREIRA, J. B.; VEDOVATO, L. R.; FERNANDES, D.; SOUZA, M. R.; BALTAR, C. S.; PERES, R. G.; WALDMAN, T. C.; MAGALHÃES, L. F. A (orgs). 
REVISTA X, Curitiba, volume 13 , n.1, p.9-34, 2018.

Dossiê Especial: Português como Língua Adicional em contextos de minorias:

(co)construindo sentidos a partir das margens

BIZON \& DINIZ (Orgs.)

Migrações Sul-Sul. 2a ed. Campinas, SP: Núcleo de Estudos de População "Elza Berquó" - Nepo/Unicamp, 2018. 976 p.

BIZON, A. C. C. Narrando o exame Celpe-Bras e o convênio PEC-G: a construção de territorialidades em tempos de internacionalização. Tese (Doutorado em Linguística Aplicada). Campinas, Universidade Estadual de Campinas, 2013.

BRASIL. Congresso Nacional. Lei n.o 13.445, de 24 de maio de 2017. Institui a Lei de Migração. Diário Oficial da União, Poder Executivo, Brasília, DF, 25 maio de 2017, Seção 1, p. 1-7. 2017a. Disponível em: <http://pesquisa.in.gov.br/imprensa/jsp/visualiza/index.jsp?.jornal=1\&pagina $=1 \&$ data $=2$ 5/05/2017>. Acesso em: 25 maio 2017.

Congresso Nacional. Decreto $\mathrm{N}^{\mathrm{o}}$ 9.199, de 20 de novembro de 2017. Regulamenta a Lei no 13.445, de 24 de maio de 2017, que institui a Lei de Migração. Diário Oficial da União, Poder Executivo, Brasília, DF, 21 de novembro de 2017, Seção 1, p. _ _ 2017b. Disponível em: <http://www.planalto.gov.br/ccivil_03/_ato2015-2018/2017/Decreto/D9199.htm>.

Acesso em: 01 fev. 2018.

CARO, E. La vulnerabilidad social como enfoque de análisis de la política de asistencia social para la población adulta mayor en México. Simposio Viejos y Viejas Participación, Ciudadanía e Inclusión Social, 51 Congreso Internacional de Americanistas. Santiago de Chile, 14 a 18 de julho de 2003.

CARMO, C. M. Grupos minoritários, grupos vulneráveis e o problema da (in)tolerância: uma relação linguístico-discursiva e ideológica entre o desrespeito e a manifestação do ódio no contexto brasileiro. In: Revista do Instituto de Estudos Brasileiros. São Paulo: Sistema Integrado de bibliotecas, Universidade de São Paulo, v.__, n. 64, ago. 2016. pp. 201-223.

CAVALCANTI, M. C. Estudos sobre educação bilíngüe e escolarização em contextos de minorias lingüisticas no Brasil. D.E.L.T.A., v. 15, n. especial, pp. 385-417.

CHARLEAUX, J. P. Como o Brasil lida com a imigração venezuelana. Nexo Jornal (online), 2018. (Reportagem). Disponível em: <https://www.nexojornal.com.br/expresso/2018/02/14/Como-o-Brasil-lida-com-aimigração-venezuelana>. Acesso em: 03 jul. 2018.

CLOCHARD, O. Les réfugiés dans le monde entre protection et illégalité. In: EchoGéo (online), n. 2, 2007.

COMITE NACIONAL PARA REFUGIADOS (CONARE). Sistema de Refúgio Brasileiro: desafios e perspectivas. Ministério da Justiça, 2016. Disponível em: <http://www.acnur.org/t3/fileadmin/scripts/doc.php?file=t3/fileadmin/Documentos/port ugues/Estatisticas/Sistema_de_Refugio_brasileiro_-_Refugio_em_numeros_-

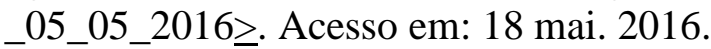


REVISTA X, Curitiba, volume 13,n.1, p.9-34, 2018.

Dossiê Especial: Português como Língua Adicional em contextos de minorias:

(co)construindo sentidos a partir das margens

BIZON \& DINIZ (Orgs.)

DINIZ, L. R. A. Política linguística do Estado brasileiro na contemporaneidade: a institucionalização de mecanismos de promoção da língua nacional no exterior. 2012. 396 fl. Tese (Doutorado em Linguística) - Instituto de Estudos da Linguagem, Universidade Estadual de Campinas, 2012.

Mercado de línguas: a instrumentalização brasileira do português como língua estrangeira. 2008. 201 fl. Dissertação (Mestrado em Linguística) - Instituto de Estudos da Linguagem, Universidade Estadual de Campinas, 2008.

LIMA, J. B.; MUÑOZ, F. P.; NAZARENO, L. A.; AMARAL, N. Refúgio no Brasil: caracterização dos perfis sociodemográficos dos refugiados (1998-2014). Brasília: Instituto de Pesquisa Econômica Aplicada - IPEA, 2017.

LOPEZ, A. P. de A. Subsídios para o planejamento de cursos de português como língua de acolhimento para imigrantes deslocados forçados no Brasil. Dissertação (Mestrado em Linguística Aplicada). Belo Horizonte, Universidade Federal de Minas Gerais, 2016.

LOPEZ, A. P. A.; DINIZ, L. R. A. Iniciativas Jurídicas e Acadêmicas para o Acolhimento no Brasil de Deslocados Forçados. Revista da Sociedade Internacional Português Língua Estrangeira, (no prelo).

MAHER, T. M. A educação do entorno para a interculturalidade e o plurilinguismo. In: KLEIMAN, A. B.; CAVALCANTI, M. C. (Orgs.) Linguística Aplicada - suas faces e interfaces. Campinas, SP: Mercado de Letras, 2007, p. 255-270.

MARANDOLA JR, E.; HOGAN, D. J. As dimensões da vulnerabilidade. São Paulo em Perspectiva, v.20, n.1, p.33- 43, 2006.

MINISTÉRIO DA JUSTIÇA E CIDADANIA (MJC). Nota à imprensa: Esclarecimento sobre concessão de vistos humanitários aos haitianos. Brasília: 2016. Disponível em: <http://justica.gov.br/noticias/nota-a-imprensa-29 2 . Acesso em: 02 out. 2016.

MIRANDA, Y. C. C. Projeto "Pelo Mundo": a configuração de uma Política Linguística em um curso de Português como Língua Adicional para candidatos ao Programa de Estudantes-Convênio de Graduação (PEC-G). 2016. 178 fl. Dissertação (Mestrado em Linguística Aplicada) - Faculdade de Letras, Universidade Federal de Minas Gerais, Belo Horizonte, 2016.

OLIVEIRA, A. T. R. Migrações internacionais e políticas migratórias no Brasil. In: Cadernos OBMigra, n. 3, v. 1, 2015.

OLIVEIRA, G. M.; SILVA, J. I. Quando barreiras linguísticas geram violação de direitos humanos: que políticas linguísticas o Estado brasileiro tem adotado para garantir o acesso dos imigrantes a serviços públicos básicos? Gragoatá, v. 22, n. 42. 2017. pp 131-153.

SÁ, P. R.; FERNANDES, D. M. A vulnerabilidade social de migrantes: uma análise qualitativa dos haitianos e sírios residentes na Região Metropolitana de Belo Horizonte 
REVISTA X, Curitiba, volume 13,n.1, p.9-34, 2018.

\section{Dossiê Especial: Português como Língua Adicional em contextos de minorias: \\ (co)construindo sentidos a partir das margens \\ BIZON \& DINIZ (Orgs.)}

a partir dos critérios da CEPAL. Anais do XX Encontro Nacional de Estudos Populacionais VII Congreso de la Asociación Latinoamericana de Población. 2016.

SÃo BERnARDO, M. A. de. Português como Língua de Acolhimento: um estudo com imigrantes e pessoas em situação de refúgio no Brasil. 2016. 206 f. Tese (Doutorado em Linguística). Programa de Pós-graduação em Linguística, Universidade Federal de São Carlos, 2016.

SEMECHECHEM, J. A. Letramento e Identidades Sociais em um município multilíngue no Paraná. Dissertação (Mestrado em Letras) - Centro de Ciências Humanas, Programa de pós-graduação em Letras, Universidade Estadual de Maringá. Maringá - PR, 2010.

SOUSA, E. N. B. A situação dos refugiados no Brasil e as políticas linguísticas: um recorte histórico. In: SOUSA, S. C. T. de; ROCA, M. del P. (orgs). Políticas Linguísticas: declaradas, praticadas e percebidas. $1^{\text {a }}$ ed. João Pessoa: Editora da UFPB, 2015. p. 423-462.

UNITED NATIONS HIGH COMMISSIONER FOR REFUGEES (UNHCR). Global trends: forced displacement in 2017. Switzerland: UNCHR, 2018. Relatório. Disponível em: <http://www.unhcr.org/statistics/unhcrstats/5b27be547/unhcr-globaltrends-2017.html>. Acesso em: 03 jul. 2018. 